\title{
Analysis of the Functional Groups Formed on the Corona-Treated Cellulose Fibre Sheet Surface by Means of Chemical Modification in Liquid Phase-ESCA Technique*
}

\author{
Atsushi Sawatari and Hiroshi Nakamura \\ Laboratory of Cellulose Science and Technology. Department of Applied Biological Science \\ Tokyo University of Agriculture and Technology, Fuchu-City, Tokyo, 183 Japan
}

\begin{abstract}
The cellulose sheet surface with various durations of corona treatment were characterized by chemical modification in liquid phase-ESCA technique. Whatman \#1 filter paper, regenerated cellulose film, handsheet from thermomechanical pulp (TMP), and handsheet from softwood bleached sulfate pulp (N.BKP) were used after washing with ethanol/benzene mixture. Carboxyl groups were found on the main chain of lignin on the surface of handsheet from TMP. However, no carboxyl groups were found on the main chain of the surface of the other cellulose sheets, namely. Whatman \#1 filter paper, regenerated cellu. lose film and handsheet from N.BKP. Carbonyl groups were introduced on the main chain of the surface of the all sheets used, after the treatment with corona discharge. Chemical modification - ESCA technique was very effective for the analysis of functional groups formed on the cellulose fibre sheet surfaces.
\end{abstract}

\section{Introduction}

Corona discharge treatment has been widely used as an essential pretreatment technique of paper web for extrusion coating of molten polyolefins onto the web [1]. However, the surface activation mechanism of paper by this treatment has not been established yet $(2,3]$. In order to elucidate the chemical changes on the surface of cellulose sheet by this treatment, the corona-treated cellulose sheets were characterized by chemical modification-ESCA technique [4]. ESCA is one of the most useful method for the analysis of po. lymer surfaces at present, and chemical modification gives chemical selectivity for the functional groups formed on the sample surfaces. Everhart et al. [4] demonstrated that the chemical modification-ESCA technique was very effective method for qualitative analysis of the functional groups on the various po.

\footnotetext{
* The main part of this report was presented at "Cellu. con 90" held at Bratislava in Aug. 1990.

この報文を「コロナ処理済セルロース䄉維シート表面の 化学:修飾－ESCA 法による研究(第 1 報), Surface Char. acterization of the Corona - Treated Cellulose Fibre Sheet by Chemical Modification - ESCA Technique (Part 1)」と する。
}

lymer surfaces. However, they also pointed out that this technique was not always approapriate for quantitative analysis. One of the authors discussed the relationship between the relative intensities $F_{15} / C_{1 s}$ obtained by this technique and the carbonyl groups content of the powder prepared by pulverizing Whatman \#1 filter paper oxidized by periodate [5]. The relative intensities $\mathrm{F}_{1 \mathrm{~S}} / \mathrm{C}_{1 \mathrm{~s}}$ were found to be almost linearly related to the carbonyl content. The authors demonstrated originally by using chemical modification-ESCA technique that corona-treated cellulose sheet surface has carbonyl groups [6].

In this study. the formation of carboxyl group on the surface of cellulose sheets were examined by us. ing chemical modification with trifluoroethanol and $\mathrm{Ca}^{2+}$ ion in liquid phase. A comparison was made be. tween introduction of carboxyl and carbonyl groups by the corona discharge treatment.

\section{Experimental}

Fig. 1 shows experimental sequence adopted in this experiment. All sheets were extracted with ethanol/ benzene mixture, since surface deposition of carbon rich extractives occur on the pulp fibres under ordin. ary conditions $[7,12,14]$. Four types of cellulose 


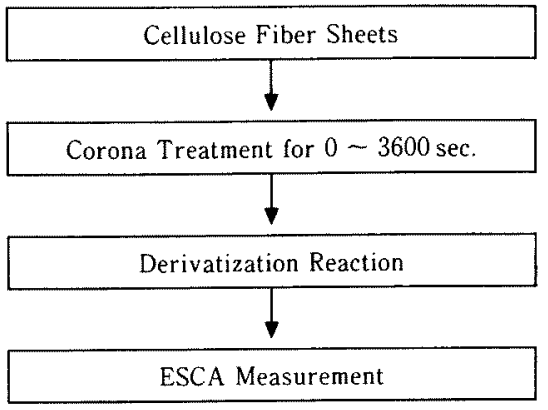

Fig. 1 Experimental Sequences

1) $-\mathrm{COOH}+\mathrm{HO}-\mathrm{CH}_{2} \cdot \mathrm{CF}_{3} \underset{\mathrm{CH}_{2} \mathrm{Cl}_{2} / \mathrm{OCC} /(\widehat{\mathrm{N}}]}{\longrightarrow}-\mathrm{COO} \cdot \mathrm{CH}_{2} \mathrm{CF}_{3}+\mathrm{H}_{2} \mathrm{O}$

2) $-\mathrm{COOH}+\mathrm{Co}^{2+} \longrightarrow\left(\begin{array}{l}-\mathrm{COO} \\ -\mathrm{COO}\end{array}\right) \mathrm{Ca}+2 \mathrm{H}^{+}$

3) $\mathrm{C}=\mathrm{O}+\mathrm{H}_{2} \mathrm{~N}-\mathrm{HN}-\left(\right.$ (E) $\underset{\mathrm{C}_{2} \mathrm{H}_{5} \mathrm{OH}}{\longrightarrow} \mathrm{C}=\mathrm{N}-\mathrm{NH}-$ (ㄹ) $+\mathrm{H}_{2} \mathrm{O}$

Fig. 2 Derivatization Reaction

sheets were treated with corona discharge in $\mathrm{O}_{2}$ atmosphere, chemically modified, and their surfaces were characterized by ESCA. Three kinds of deriva. tives were used for ESCA measurement as shown in Fig. 2. If the sample surface possesses carboxyl groups, the groups react with trifluoroethanol (TFE) to give trifluoroethylester. Carboxyl groups also react with $\mathrm{Ca}^{2+}$ ion to give calcium carboxylate. After de. rivatization, $F_{1 s}$ peak or $\mathrm{Ca}_{2 \mathrm{P}}$ peak were observed in ESCA spectra. If the sample surface has carbonyl groups, they react with pentafluorophenylhydrazine (PFPH) giving pentafluorophenylhydrazone, and then $F_{1 s}$ peak should appear in ESCA spectra.

\subsection{Sample Sheets}

Four types of the cellulose sheets were prepared for the following experiments. Radiata pine TMP was beaten to $170 \mathrm{~mL}$ C.s.f. by Valley beater, and the handsheets were made from beaten TMP. Handsheets were also made from N.BKP beaten by PFI mill to $400 \mathrm{~mL}$ C.s.f. Handsheet from TMP, handsheet from $\mathrm{N} \cdot \mathrm{BKP}$ and Whatman \#1 filter paper were Soxhlet extracted with ethanol/benzene mixture for $10 \mathrm{~h}$. After the extraction treatment, the sample sheets were air-dried. Commercially available cellophane was im. mersed in a stream of tap water over night. The tap water-washed cellophane was washed with distilled water and organic solvents, and dried while applying a tension in the atmosphere of $20^{\circ} \mathrm{C}$ and $65 \% \mathrm{RH}$. The air-dried sheets and films were stored in a silica gel containing desiccator.

\subsection{Corona Discharge Treatment}

A batch type discharging equipment [8] was used in this experiment. Discharging conditions were as follows: discharging voltage $13 \mathrm{kV}$, discharging fre quency $50 \mathrm{~Hz}$, discharging power 4.01 watts, dis. charging period $0-3600 \mathrm{sec}$, electrode size $100 \mathrm{~mm}$ $\times 100 \mathrm{~mm} \times 5 \mathrm{~mm}$, atmosphere $\mathrm{O}_{2}$ gas flow of 80 $\mathrm{mL} / \mathrm{min}$, gap between the electrodes $5.2 \mathrm{~mm}$, thick. ness of dielectrics (glass plate) $2.9 \mathrm{~mm}$, air gap 2.2 $\mathrm{mm}$, temperature $20^{\circ} \mathrm{C}$ and pressure atmospheric pressure

\subsection{Chemical Modification (Derivatization)}

Derivatizations were carried out by the following procedures. Corona-treated sheet samples were reacted with three kinds of reagents, respectively.

\subsubsection{Derivatization with TFE}

$1 \mathrm{~mL}$ of TFE was added in the mixture of $2 \mathrm{~mL}$ pyridine, $400 \mathrm{mg}$ of dicyclohexylcarbodiimide (DCC) and $30 \mathrm{~mL}$ of dichloromethane. The sample sheets were immersed in $33 \mathrm{~mL}$ of the above-described reagent in $200 \mathrm{~mL}$ glass stoppered Erlenmeyer flask kept shaking for $15 \mathrm{~h}$ at $20^{\circ} \mathrm{C}$. After washing with anhy. drous ether, the treated sample sheets reacted were Soxhlet extracted with anhydrous ether for $12 \mathrm{~h}$. The extracted sample sheets were then dried in air at room temperature and stored in silica gel containing desiccator with brownnish color. After vacuum drying at room temperature, the derivatized sample sheets were used for the next ESCA measurement.

\subsubsection{Derivatization with $\mathrm{Ca}^{2+}$ Ion}

$0.34 \mathrm{mN}$ calcium acetate solution was prepared by diluting $0.5 \mathrm{M}$ calcium acetate to $0.34 \mathrm{mN}$ and $\mathrm{pH}$ of the solution was controlled to $6.5-7.0$ by adding appropriate volume of acetic acid and of $0.34 \mathrm{mN}$ cal. cium hydroxide. The $200 \mathrm{~mL}$ glass stoppered Erlenmeyer flask containing corona-treated sample sheets and $100 \mathrm{~mL}$ of $0.1 \mathrm{~N} \mathrm{HCl}$ was kept shaking for 15 $\min$ at $20^{\circ} \mathrm{C}$. This procedure was repeated 2 times furthermore and washed with distilled water. And then, the sample sheets were immersed in $100 \mathrm{~mL}$ of 
the $0.34 \mathrm{mN}$ calcium acetate solution and kept shak ing for $15 \mathrm{~min}$. After washing with distilled water. the sample sheets were dried in air.

\subsubsection{Derivatization with PFPH}

$0.1 \mathrm{~g}$ of PFPH (Aldrich Chemical Company, Inc., was dissolved in $100 \mathrm{~mL}$ of anhydrous ethanol. Sam. ple sheets were immersed in $50 \mathrm{~mL}$ of this solution in $200 \mathrm{~mL}$ glass stoppered Erienmeyer flask and kept shaking for $10 \mathrm{~min}$ at $20^{\circ} \mathrm{C}$. After washing with anhydrous benzene and acetone, the reacted sample sheets were dried in air.

\subsection{ESCA Measurement}

JOEL type JPS- 80 was used as a ESCA spectrometer, and JPS- 80 Multiground ESX was used to analyse the obtained data. Measuring conditions were as follows: $\mathrm{X}$-ray source $\operatorname{MgK} \alpha(1253.6 \mathrm{eV})$, accerelating voltage $10.0 \mathrm{kV}, X$-ray current $10.0 \mathrm{~mA}$, scanning range $280-300 \mathrm{eV}$ for $\mathrm{C}_{\mathrm{is}}$ peak, $680-$ $700 \mathrm{eV}$ for $\mathrm{F}_{1 \mathrm{~s}}$ peak, $340-360 \mathrm{eV}$ for $\mathrm{Ca}_{2 \mathrm{P}}$ peak, degree of vacuum $10^{-6} \mathrm{~Pa}$, times of scanning 30 times and without the correction for charge up effect.

\section{Results and Discussion}

Changes in $F_{1 S}$ peak and $C_{1}$ peak followed by the increase in duration of corona treatment are shown in Fig. 3 for TMP handsheet derivatized with TFE. There are no changes in $C_{1 s}$ peak and notable in-

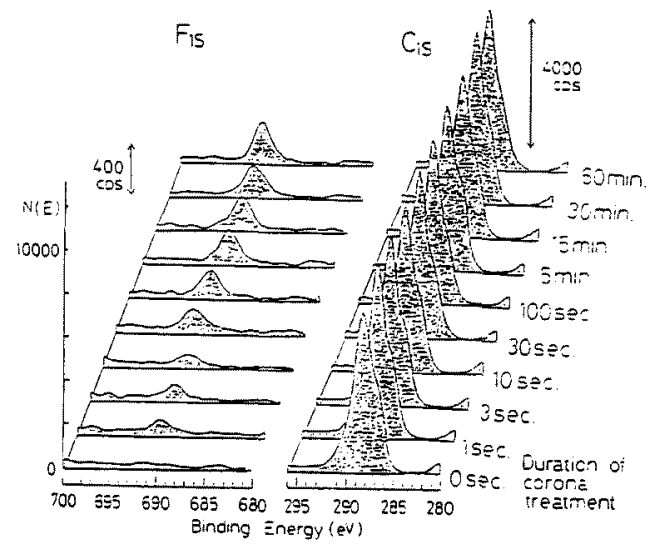

Fig. 3 Changes in $F_{1}$ peak and $C_{15}$ peak of handsheet from TMP by the increase in duration of corona treatment. Derivatization was carried out by using TFE/ DCC/Dichloromethane system after corona treatment. TFE: 2,2,2- Trifluoroethanol, DCC: Dicyclohexylcarbodiimide. crease in $F_{1 s}$ peak intensity with the increase in duration of corona treatment. These results show that carboxyl groups are found on the surface of the corona-treated handsheet from TMP. Two processes may be attributable for the chemical changes on the surface layer of these sample system [7]. One is the formation of some oxygen containing functional groups on the surface layer of frame work or of polymeric main chain of constituent polymers. Another is some scissions or cleavages of polymeric chain. Therefore, compounds with lower molecular weight will be formed on the surface layer of the consituent polymer. As the authors adopted the chemical modification in liquid phase in this study, these compounds with lower molecular weight may be washed out from the surface of the corona-treated cellulose sheet. Therefore. ESCA spectra, which involved in this chemical modification in liquid phase-ESCA technique. are considered to give the information on the main chain residue on the surface layer. Verification of the above assumption will be furthermore discussed in another report [7]. According to the abovedescribed reason, it should be considered that the carboxyl groups are introduced onto the main chain of the surface of TMP handsheet by the corona discharge.

Changes in relavite intensity $\left(\mathrm{F}_{1 \mathrm{~S}} / \mathrm{C}_{1 \mathrm{~S}}\right)$, ratio of number of atoms $\left(\mathrm{N}_{F} / \mathrm{N}_{C}\right)$ and number of carboxyl groups per total number of carbon atom by the corona treatment were summerized in Table 1 for handsheets from TMP. Ratios of number of atoms $\left(\mathrm{N}_{\mathrm{F}} / \mathrm{N}_{\mathrm{C}}\right)$ were calculated from relative intensities $\left(\mathrm{F}_{1 \mathrm{~S}} / \mathrm{C}_{\mathrm{IS}}\right)$ by using Ebel-Hirokawa's method and Physical Electronic's Table concerning atomic sensitivity factor $[9-11)$. From Table 1, 2.7 carboxyl groups per one thousand of carbon atoms, that is, 2.4 carboxyl per one hundred of $C_{9}$ units of lignin were considered to be introduced onto the TMP sheet surface at its maximum.

On the other hand, no $F_{1}$ peak was observed in ESCA spectra of Whatman \#1 filter paper, regenerated cellulose film and N.BKP handsheet (Fig. 4, Fig. 5 and Fig. 6, respectively). This shows that carboxyl groups cannot be detected on the surface of these cel. lulose sheets by this technique. Accordingly, it may be considered that no carboxyl groups are introduced onto the main chain of the three kinds of cellulose 
Table 1 ESCA Relative Intensity and Number of Carboxyl Groups per Total Carbon Atom for Handsheet from TMP Derivatized with TFE/DCC/dichloromethane System after Corona Treatment

\begin{tabular}{|c|c|c|c|c|c|}
\hline \multirow{2}{*}{$\begin{array}{l}\text { Duration } \\
\text { of corona } \\
\text { treatment }\end{array}$} & \multicolumn{2}{|c|}{ Area $(\mathrm{cps} \cdot \mathrm{eV})$} & \multirow{2}{*}{$\begin{array}{c}\text { Relative } \\
\text { intensity } \\
\left(\times 10^{2}\right)\end{array}$} & \multirow{2}{*}{$\begin{array}{c}\text { Atom } \\
\text { ratio }^{*} \\
\left(\times 10^{3}\right)\end{array}$} & \multirow{2}{*}{$\begin{array}{c}\text { Carboxyl/C } \\
\left(\times 10^{3}\right)\end{array}$} \\
\hline & $F_{1 s}$ & $\mathrm{C}_{1 \mathrm{~s}}$ & & & \\
\hline $0 \mathrm{sec}$ & 37 & 15600 & 0.24 & 0.49 & 0.16 \\
\hline $1 \mathrm{sec}$ & 140 & 16500 & 0.85 & 1.74 & 0.58 \\
\hline $3 \mathrm{sec}$ & 149 & 15500 & 0.96 & 1.97 & 0.66 \\
\hline $10 \mathrm{sec}$ & 165 & 16300 & 1.01 & 2.07 & 0.69 \\
\hline $30 \mathrm{sec}$ & 305 & 15500 & 1.97 & 4.03 & 1.34 \\
\hline $100 \mathrm{sec}$ & 371 & 15800 & 2.35 & 4.81 & 1.60 \\
\hline $5 \mathrm{~min}$ & 387 & 15800 & 2.45 & 5.02 & 1.67 \\
\hline $15 \mathrm{~min}$ & 400 & 16100 & 2.48 & 5.09 & 1.70 \\
\hline $30 \mathrm{~min}$ & 515 & 16400 & 3.14 & 6.44 & 2.15 \\
\hline $60 \mathrm{~min}$ & 633 & 15900 & 3.98 & 8.16 & 2.72 \\
\hline
\end{tabular}

*: : Calculated from relative intensity $\times 0.205$. The coefficient 0.205 is quoted from Physical Electronic's Table 5 concerning atomic sensitive factors (ASF).

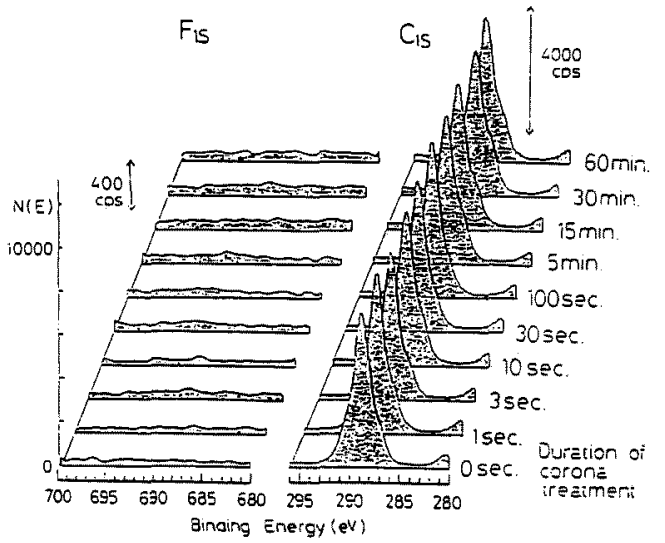

Fig. 4 Changes in $F_{1}$ s peak and $C_{1 s}$ peak of Whatman \#1 filter paper by the increase in duration of corona treatment. Derivatization was carried out by using the same method as one in Fig. 3.

sheets. In addition, it is interesting in Fig. 5 that spectral intensity of the low binding energy compo. nent of $C_{1 s}$ peak increases with the increase in duration of corona treatment in the case of regenerated cellulose film. At present, the reason for this phe. nomenon can not be envisaged clearly. Relative intensities of $F_{15}$ peak to $C_{1 s}$ peak $\left(F_{1 S} / C_{1 S}\right)$ were plotted against the logarithm of duration of corona treatment $(\log t)$ as shown in Fig. 7 . Fig. 7 shows that the rela. tive intensity $\left(F_{15} / C_{15}\right)$ increases with the increase in

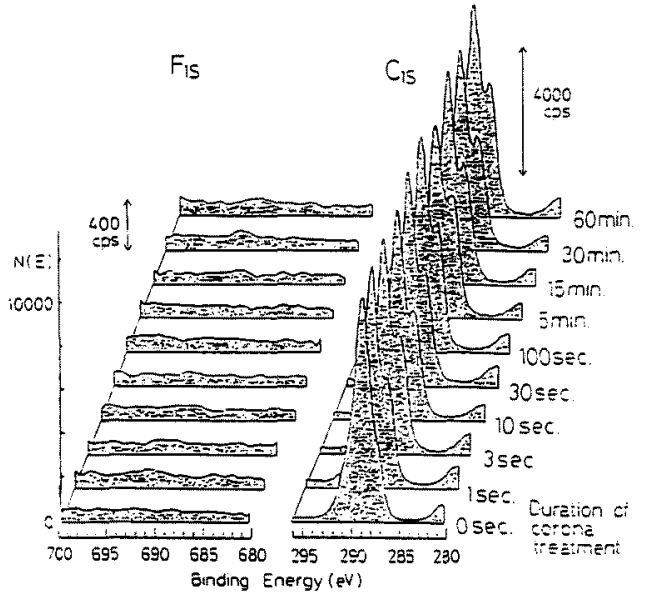

Fig. 5 Changes in $F_{15}$ peak and $C_{1 s}$ peak of regenerated cellulose film by the increase in duration of corona treat. ment. Derivatization was carried out by using the same method as one in Fig. 3.

the duration of corona treatment for TMP handsheet, but any changes in the relative intensities were not found in the other cellulose sheets than the TMP sheet. The TMP handsheet samples have lignin rich surface [12], but Whatman \#1 filter paper, regenerated cellulose film and N.BKP handsheet have carbohydrate rich surface $[12,13]$. Usually the surface layers of these sheets have considerable quantities of extractives, but after extracting with ethanol/benzene 


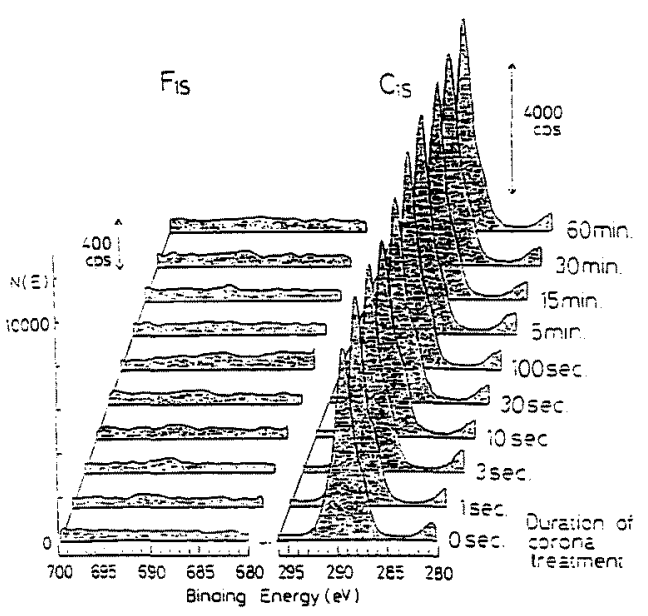

Fig. 6 Changes in $F_{1 s}$ peak and $C_{1}$ peak of handsheet from softwood bleached sulfate pulp (abbreviated as $N$ BKP hereafter) by the increase in duration of corona treatment. Derivatization was carried out by using the same method as one in Fig. 3.

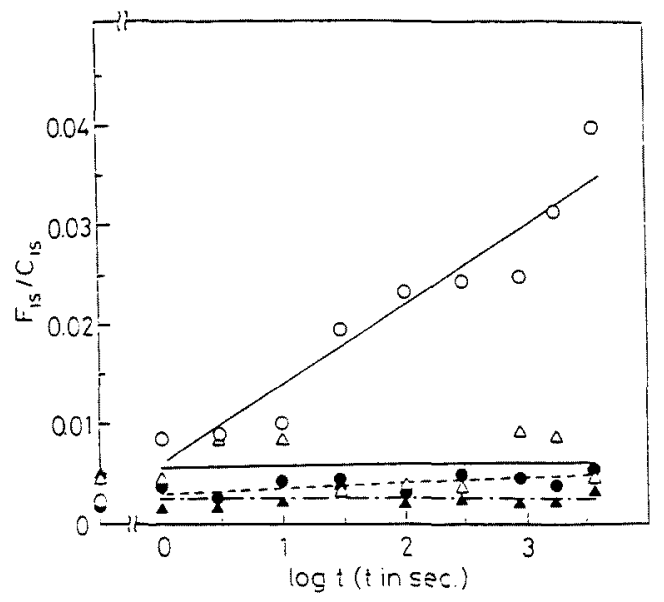

Fig. 7 Relationship between ESCA relative intensity $\left(F_{1 S} / C_{1 S}\right)$ and logarithm of the duration of corona treat. ment $(\log t)$ for various cellulose fibre sheets which were derivatized with TFE/DCC/Dichloromethane sys. tem after corona treatment. $O$ : TMP handsheet, $\triangle$ : Whatman \#1 filter paper, : Regenerated cellulose film and $\mathbf{A}$ : BKP handsheet.

mixture. the surface layers of the sheets have almost no extractives $[12,14-16]$. In this experiment, there. fore, all sheet samples were used after extracting with ethanol/benzene mixture or other organic sol. vents. From Fig. 7, a site of lignin rich surfaces seem

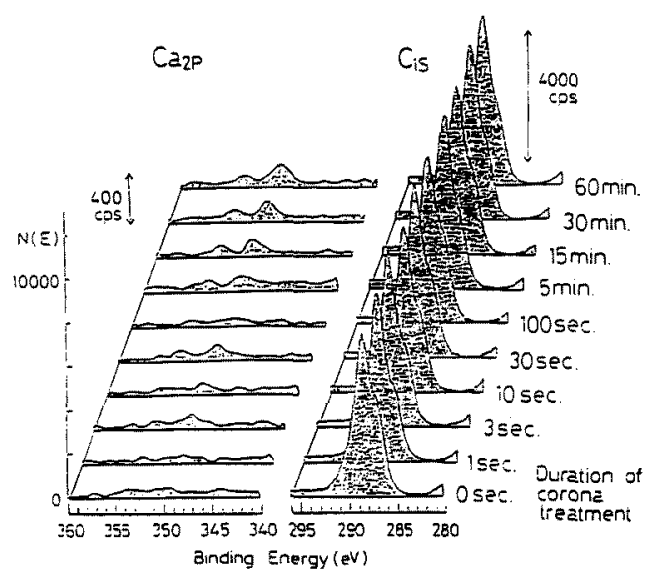

Fig. 8 Changes in $\mathrm{Ca}_{2}$ peak and $C_{1 S}$ peak of handsheet from TMP by the increase in duration of corona treatment. Derivatization was carried out by using $\mathrm{Ca}^{2+}$ ion after corona treatment.

to be oxidized by the corona discharge to carboxyl groups, but sites of carbohydrate rich surfaces seem to be not oxidized to carboxyl groups. However, strictly speaking, it should be considered that the car. boxyl groups are not introduced onto the main chain of the cellulose and hemicellulose on the surface layer of the three kinds of the cellulose sheets, for the above-described reason. It can be thought from Fig. 7 that corona discharge brought about carboxyls on the main chain of the lignin of the TMP handsheets.

Change in $\mathrm{Ca}_{2 \mathrm{P}}$ peak and $C_{1 \mathrm{~s}}$ peak by the increase in duration of corona treatment are shown in Fig. 8 for the handsheet from TMP. There are no changes in $C_{15}$ peak, but a significant increase in $\mathrm{Ca}_{2}$ peak intensity with the increase in duration of corona treatment. That is, carboxyl groups seem to be introduced onto the surface of the handsheet from TMP.

On the contrary, no $\mathrm{Ca}_{2 \mathrm{P}}$ peaks were found in ESCA spectra of Whatman \#1 filter paper, regenerated cellulose film and N.BKP handsheet (Fig. 9 . Fig. 10 and Fig. 11, respectively). This shows that carboxyl groups cannot be detected on the surface of these cellulose sheets by using this technique. In addition, it is interesting in Fig. 10 that spectral intensity of the low binding energy component of $C_{15}$ peak also increases with the increase in the duration of corona treatment in the case of regenerated cellulose film, in a similar manner as in Fig. 5. 


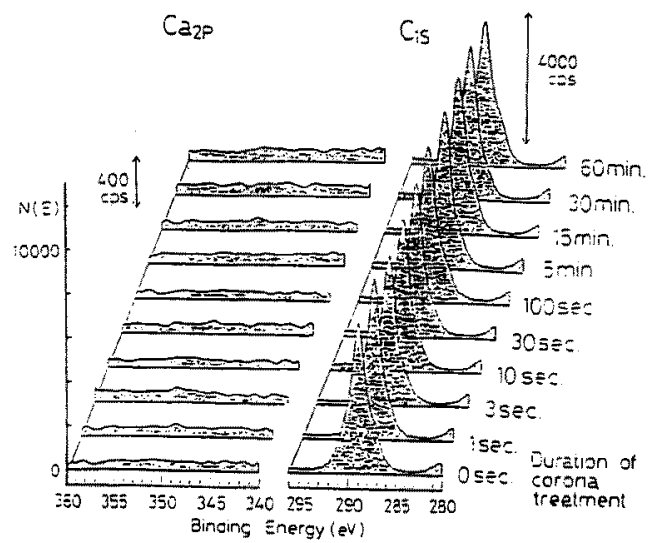

Fig. 9 Changes in $\mathrm{Ca}_{2 p}$ peak and $C_{1}$ peak of Whatman \#1 filter paper by the increase in duration of corona treatment. Derivatization was carried out by using $\mathrm{Ca}^{2+}$ ion after corona treatment.

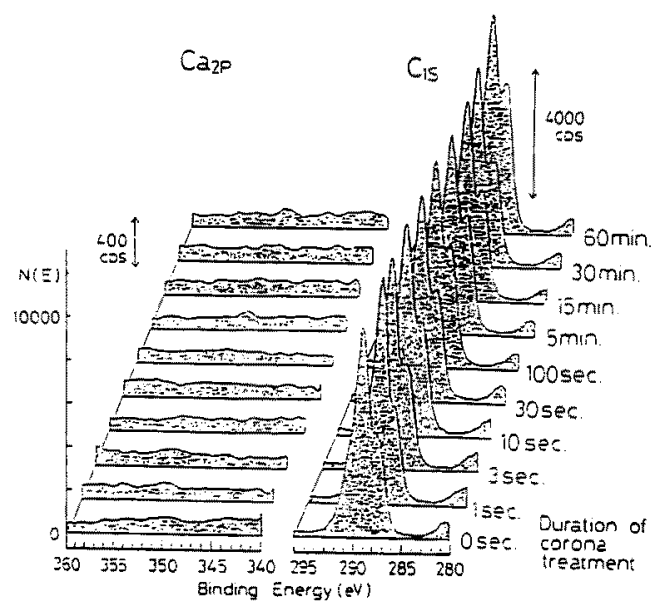

Fig. 10 Changes in $\mathrm{Ca}_{2} \mathrm{P}$ peak and $C_{1 s}$ peak of regener. ated cellulose film by the increase in duration of corona treatment. Derivatization was carried out by using $\mathrm{Ca}^{2+}$ ion after corona treatment.

Relative intensity of $\mathrm{Ca}_{2 \mathrm{P}}$ peak to $\mathrm{C}_{1 \mathrm{~s}}$ peak $\left(\mathrm{Ca}_{2 \mathrm{P}}{ }^{\prime}\right.$ $\left.C_{15}\right)$ were plotted against the logarithm of duration of corona treatment $(\log \mathrm{t})$ as shown in Fig. 12. From Fig. 12, lignin rich surfaces seem to be oxidized by the corona discharge to carboxyl groups, but carbohy. drate rich surfaces seem to be not oxidized to carboxyl groups.

Changes in $F_{1 s}$ peak according to the progress of corona treatment shown in Figs. $3-7$ are consistent with changes in $\mathrm{Ca}_{2}$ p peak in Figs. $8-12$.

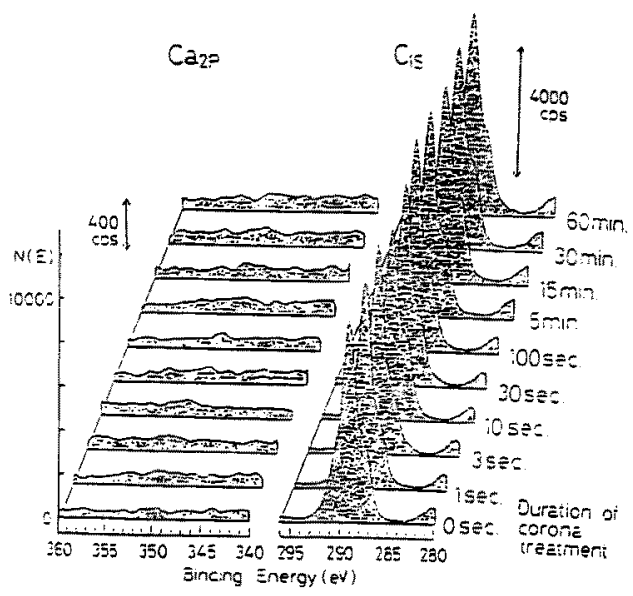

Fig. 11 Changes in $C_{2} P$ peak and $C_{1 s}$ peak of hand sheet from N.BKP by the increase in duration of corona treatment. Derivatization was carried out by using $\mathrm{Ca}^{2+}$ ion after corona treatment.

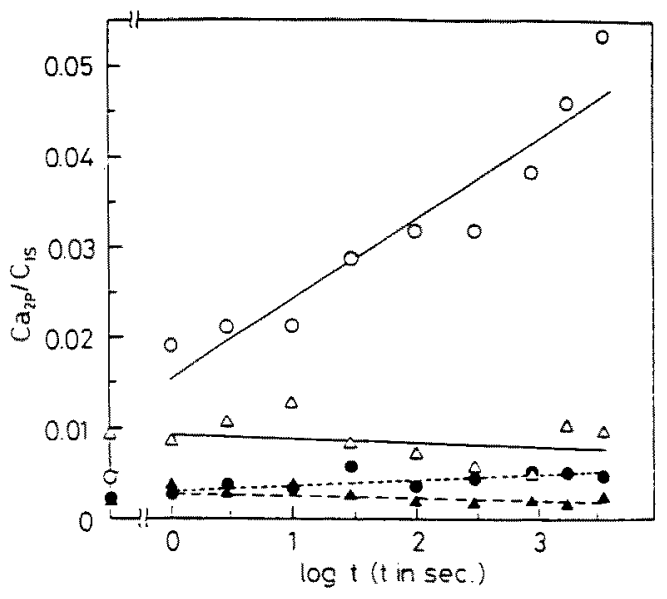

Fig. 12 Relationship between ESCA relative intensity $\left(\mathrm{Ca}_{2 \mathrm{p}} / \mathrm{C}_{1 \mathrm{~s}}\right)$ and logarithm of the duration of corona treatment $(\log \mathrm{t})$ for various cellulose fiber sheets which were derivatized with $\mathrm{Ca}^{2+}$ ion after corona treatment. $\mathrm{Ca}_{2 \mathrm{P}}$ peak intensity was calculated from the summation of $\mathrm{Ca}_{2 \mathrm{P}}{ }^{3 / 2}$ and $\mathrm{Ca}_{2 \mathrm{P}}{ }^{1 / 2}$. O : TMP handsheet. $\triangle$ : Whatman \#1 filter paper. Regenerated cellulose film and $\boldsymbol{\Delta}$ N.BKP handsheet.

It can be summarized from Figs. 3-12 that car. boxyl groups were found on the surface of the TMP sheet increasingly according to the progress of corona discharge by this chemical modification in liquid phase-ESCA technique, but no carboxyl groups were found on the surface of the other cellulose sheets than 
TMP handsheet by this technique. These results are attributable to the carboxyl formation on the main chain of the lignin rich surface of TMP sheet, and no carboxyl formation on the main chain of the cellulose rich surface of the other sheets.

In addition, it is also interesting that spectral intensity at the low binding energy component of $C_{i s}$ peak increases with the increase in duration of corona treatment in the case of regenerated cellulose film. It may be suggested that the discharge brought about some carbon rich components on the surface of the regenerated cellulose film.

Changes in $F_{15}$ peak and $C_{15}$ peak according to the increase in duration of corona discharge treatment are shown in Fig. 13 for TMP handsheet derivatized with PFPH. It can be seen from Fig. 13 that there are no changes in $C_{1 s}$ peak and remarkable increase in $F_{1 s}$ peak intensity with the increase in the duration. This shows that carbonyl groups can be detected on the surface of TMP handsheet by this technique. Car. bonyl groups apparently seems to be introduced onto the surface of handsheet from TMP. Strictly speaking. it should be considered that the carbonyl groups are introduced onto the main chain of the surface of the TMP handsheet by the formerly described reason. Re. lative intensities of $F_{1 s}$ peak to $C_{1 s}$ peak $\left(F_{1 s} / C_{1 S}\right)$ were plotted against logarithm of the duration of corona treatment $(\log t)$ in Fig. 14. Fig. 14 shows that

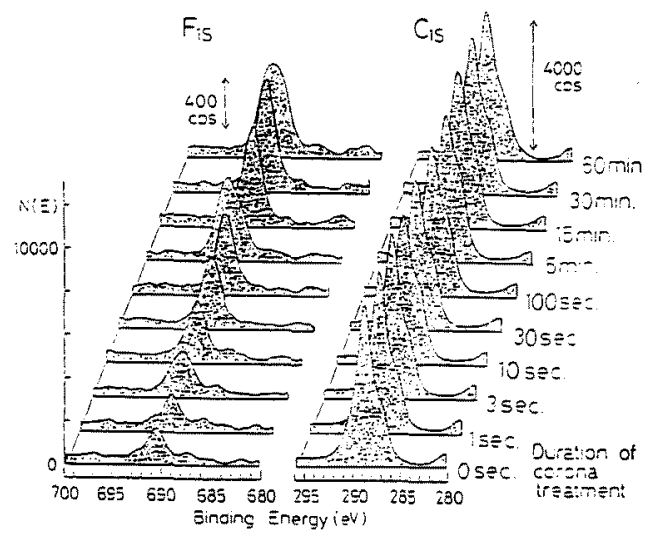

Fig. 13 Changes in $F_{15}$ peak and $C_{15}$ peak of handsheet from TMP by the increase in duration of corona treatment, Derivatization was carried out by using PFPH/ ethanol system after corona treatment. PFPH: Pentafluorophenylhydrazine. the relative intensity $\left(\mathrm{F}_{1 \mathrm{~S}} / \mathrm{C}_{1 \mathrm{~S}}\right)$ increases with the increase in the duration of corona treatment for all. sheets used. From Fig. 14, both lignin rich surfaces and carbohydrate rich surfaces seem to be oxidized to carbonyl groups by corona discharge. For the same reason as above-described one, it should be considered that the carbonyl groups are introduced onto the main chain of the surface of all sheets used. The numbers of the introduced carbonyls on the TMP sheet chemically modified with PFPH were calculated by the same method used in Table 1, as shown in Table 2. From Table 1 and 2, large quantities of car. bonyl groups were introduced in comparison to carboxyl groups.

It will be a future problem that information about surface concentration of any washable compounds with low molecular weight will be required to under. stand the state of the corona-treated surface of var. ious cellulose sheets $(6,7)$.

\section{Conclusion}

About 2.4 carboxyl groups per one hundred of $\mathrm{C}_{9}$ units of lignin were found on the surface of the corona-treated TMP handsheet at its maximum, while about 10.9 carbonyl groups per one hundred of $C_{9}$ units of lignin were found on the surface of the sheet. On

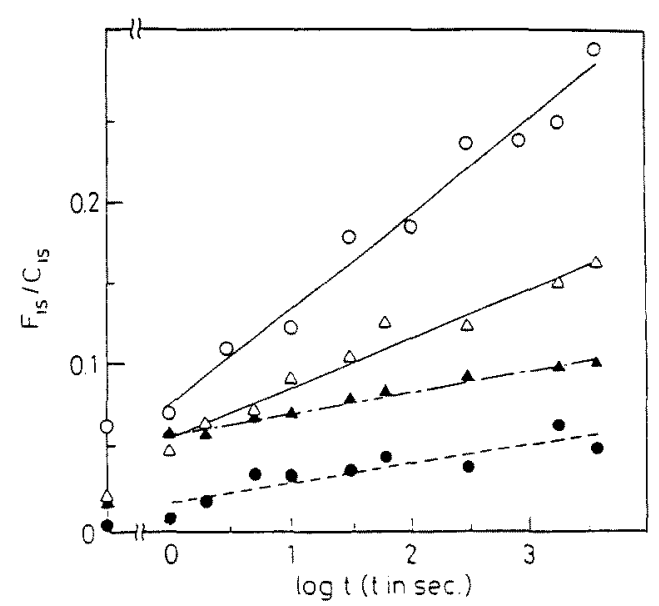

Fig. 14 Relationship between ESCA relative intensity $\left(F_{1 S} / C_{1 S}\right)$ and logarithm of the duration of corona treat. ment $(\log t)$ for various cellulose fiber sheets which were derivatized with $\mathrm{PFPH}$ after corona treatment. $\mathrm{O}$ : TMP handsheet, $\triangle$ : Whatman \#1 filter paper, $O$ : Re. generated cellulose film and $\boldsymbol{\Delta}$ : N.BKP handsheet. 
Table 2 ESCA Relative Intensity and Number of Carbonyl Groups per Total Carbon Atom for Handsheet from TMP Derivatized with PFPH/ethanol System after Corona Treatment

\begin{tabular}{|c|c|c|c|c|c|}
\hline \multirow{2}{*}{$\begin{array}{l}\text { Duration } \\
\text { of corona } \\
\text { treatment }\end{array}$} & \multicolumn{2}{|c|}{ Area $(\mathrm{cps} \cdot \mathrm{eV})$} & \multirow{2}{*}{$\begin{array}{c}\text { Relative } \\
\text { intensity } \\
\left(\times 10^{1}\right)\end{array}$} & \multirow{2}{*}{$\begin{array}{c}\text { Atom } \\
\text { ratio* } \\
\left(\times 10^{2}\right)\end{array}$} & \multirow{2}{*}{$\begin{array}{c}\text { Carbonyl/C } \\
\left(\times 10^{3}\right)\end{array}$} \\
\hline & $F_{\text {is }}$ & $\mathrm{C}_{1 \mathrm{~S}}$ & & & \\
\hline $0 \mathrm{sec}$ & 870 & 13,200 & 0.66 & 1.35 & 2.70 \\
\hline $1 \mathrm{sec}$ & 930 & 13,200 & 0.70 & 1.44 & 2.89 \\
\hline $3 \mathrm{sec}$ & 1,510 & 14.000 & 1.08 & 2.21 & 4.42 \\
\hline $10 \mathrm{sec}$ & 1,660 & 13,600 & 1.22 & 2.50 & 5.00 \\
\hline $30 \mathrm{sec}$ & 2,440 & 13,600 & 1.79 & 3.68 & 7.36 \\
\hline $100 \mathrm{sec}$ & 2.530 & 13.600 & 1.86 & 3.81 & 7.63 \\
\hline $5 \min$ & 3,290 & 13,900 & 2.37 & 4.85 & 9.70 \\
\hline $15 \min$ & 3,470 & 14,600 & 2.38 & 4.87 & 9.74 \\
\hline $30 \mathrm{~min}$ & 3,340 & 13,400 & 2.49 & 5.11 & 10.22 \\
\hline $60 \mathrm{~min}$ & 4.010 & 13,600 & 2.95 & 6.04 & 12.09 \\
\hline
\end{tabular}

* :The atom ratio was calculated by the same method as one in Table 1.

the other hand, no carboxyl goups were found on the surface of other cellulose sheets, while about $6.8 \mathrm{car}$. bonyl groups per one hundred of glucose residues were found on the surface of Whatman \#1 filter pa. per, about 1.5 carbonyls per one hundred of glucose residues on regenerated cellulose film and about 2.1 carbonyl per one hundred of $C_{5}$ units of xylose residues on N.BKP handsheet. These values were obtained by assuming that Ebel-Hirokawa's rule [9] holds in the cellulose sheet sample system. However. it is important that the above-described information was originally obtained by adapting this chemical modification in liquid phase- ESCA technique to corona-treated cellulose sheets.

\section{References}

1. R. H. Cramm. "Pulp and Paper", Vol. IV J. P. Casey Ed., p. 2530-2531, Wiley-Interscience, N. Y. (1983).

2. D. A. 1. Goring, Pulp \& Paper Mag, Can. 68, T372 (1967).

3. G. Suranyi, D. G. Gray and D. A. I. Goring. Tappi, $63(4), 153$ (1980).

4. D. S. Everhart and C. N. Reilley, Anal. Chem., 53 , 665 (1981).

5. S. Nishiyama and A. Sawatari, Abstr. 41th Annual Meeting of Japan Wood Res. Soc., p. 515 (1991).

6. A. Sawatari, Y. Hayashi, and T. Kurihara, "CEL.
LULOSE -structural and functional aspects", J. F. Kennedy, G. O. Phillips, and P. A. Williams Eds., Ellis Horwood Limited, Chichester, p. 137 (1989)

7. S. Nishiyama, N. Funato, and A. Sawatari, Abstr. 1992 Jpn. Tappi Pulp \& Paper Res. Conf., p. 84 (1992).

8. T. Chou, K. Murakami, and I. Imamura, J. Soc. Materials Sci., Jpn.. 26, 477 (1977).

9. M. F. Ebel, H. Ebel, and K. Hirokawa, Spectrochim. ica Acta, 37B, 461 (1982).

10. J. H. Scofield, J. Electron Spectroscopy and Related Phenomena, 8, 129 (1976).

11. "Handbook of X-ray Photoelectron Spectroscopy, - A Reference Book of Standard Data for Use in X-ray Photoelectron Spectroscopy", G. E. Muilenberg Ed., Pub. by PERKIN ELMER Corp. Physical Electro. nics Div., p. 188.

12. G. M. Dorris and D. G. Gray, Cellulose Chem. Technol., 12, 721 (1978).

13. D. G. Gray, Cellulose Chem. Technol., 12, 735 (1978)

14. S. Katz and D. G. Gray, Svensk Papperstidn., 83, 226 (1980).

15. S. Takeyama and D. G. Gray, Trans. CPPA. TR-61 (1980).

16. N. Ohno and A. Sawatari, Japan Tappi J., 46, 1295 (1992). 